\title{
A prion-linked psychiatric disorder
}

$T^{\text {he }}$ he finding that new variant CreutzfeldtJakob disease, the recently discovered prion disease thought to be associated with ingestion of bovine offal ${ }^{1}$, has a prolonged course and can present with psychiatric symptoms ${ }^{2}$ raised the possibility that hereditary forms of prion disease may also be associated with serious psychiatric disorders. We have sequenced the open reading frame of the prion protein $(\mathrm{PrP})$ gene isolated from 10 patients with a strong family history of psychiatric illness. In one patient we discovered a previously undescribed sequence alteration, N171S, which raises the possibility of a significant extension in the pathologies associated with inherited prion diseases.

We studied 10 individuals from families with a high incidence of schizophrenic or schizoaffective (DSM-IV) disorders. We sequenced the prion protein gene (PRNP) directly from polymerase chain reaction products amplified from peripheral blood leukocytes from each of these patients. In nine families where the disease was confined to schizophrenia we found no mutations, but one other patient exhibited a previously undescribed adenine to guanine substitution, resulting in an asparagine to serine alteration at codon 171 of the PRNP gene. The individual was a heterozygote for codon 129 , a site of a common polymorphism ${ }^{3}$, and by subsequent cloning and sequencing we found that the mutated allele encoded valine at codon 129. We also found this genotype in five of eleven living relatives of the patient (Fig. 1).

The patient suffered persecutory delusions, auditory hallucinations, severe depression and had a history of suicide attempts and violent behaviour over a 10 -year period. Neurological symptoms such as ataxia or dementia, typical of known prion diseases ${ }^{4}$, were absent. Of the other members of the patient's family identified as mutation carriers, the patient's mother has dementia and urinary incontinence and a 35-year history of similar psychiatric symptoms. The

\section{Trapping speciation}

Chromosome rearrangements are often an important factor in the origin of new species $^{1}$. They have a potential to affect the fitness of hybrids, and so to stop gene flow and strengthen genetic divergence between intraspecific chromosomal races $^{2}$. Debate still rages over which model ${ }^{1}$ best explains chromosomal speciation, the main difficulty being the lack of historical records. We now present data that may represent just such a record.

In the small village of Migiondo (North-

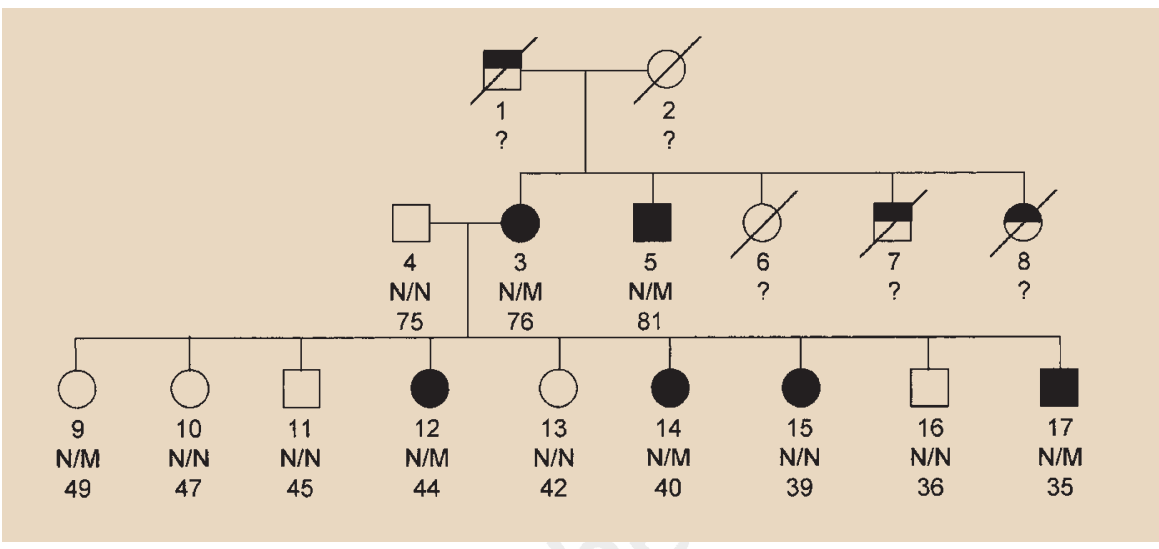

Figure 1 Family pedigree. Squares denote males and circles denote females. Black symbols indicate definitive psychiatric disorders affecting family members and half-black symbols denote the family members with plausible psychiatric symptoms. The age of each individual is shown below the symbols. N, normal; $\mathrm{M}$, mutant allele. The first identified patient was individual number 12.

patient's uncle presented seven years ago with abnormal behaviour including apathy, social withdrawal, mutism and occasional violence, and subsequently developed urinary and faecal incontinence, walking difficulty and dementia. Two affected siblings have a psychiatric history of alternating severe depression and aggressiveness and one of them also has persecutory delusions and auditory hallucinations whereas the third was symptom-free.

This pedigree exhibits incomplete penetrance and variable expression of the disease, typical of inherited prion diseases. None of these patients can be easily classified within well-defined clinical categories and all responded poorly to conventional therapies. Of the five siblings with normal PRNP genotype, four have had no psychiatric or neurological illness whereas the fifth has bipolar disorder, characterized by sequences of euphoric, depressive and normal periods. This patient lacks the complex disease progression seen in the family members with N171S.

Our findings indicate that inherited prion diseases might include serious atypical psychiatric disorders, in addition to the welldefined strictly neurological pathologies ${ }^{4}$ and personality changes ${ }^{5}$. An analysis of a large number of affected families and individuals known to be free of any mental disorders will establish the frequency of the new PRNP genotype and the strength of its association with mental disease.

Helena B. Samaia, Jair de Jesus Mari Department of Psychiatry,

Federal University of São Paulo, São Paulo, Brazil

Homero P. Vallada

Department of Psychiatry, University of São Paulo, São Paulo, Brazil

Ricardo P. Moura, Andrew J. G. Simpson, Ricardo R. Brentani*

Ludwig Institute for Cancer Research,

Rua Professor Antonio Prudente, 109,

São Paulo, Brazil

e-mail:ludwig0@node1.com.br

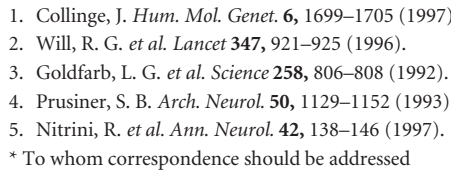

ern Italy) Hauffe and Searle ${ }^{3}$ found only one of the two chromosomal races of the common house mouse Mus musculus domesticus that we had described ${ }^{4} 10$ years earlier. All over Europe, house mouse populations with the standard karyotype (diploid number $2 n=40$ all-telocentric chromosomes) are patchily distributed and parapatrically intermingled with more than 40 other populations. These other populations have reduced chromosome numbers following telocentric fusion and fixation of metacentric chromosomes produced by robertsonian translocation. Robertsonian chromosomes (Rbs) occur at an extremely high rate, and of the 171 possible telocentric arm combinations that can form Rbs, 124 have been observed. Northern Italy hosts the vast majority of them ${ }^{5}$. Theoretically, each of the chromosomal races may be on the way to speciation ${ }^{1,3}$.

In the area north of Milan, we and others $^{5,6}$ have been trapping mice for 20 years and have described a population, Milan I, with $2 n=24$, containing 8 homozygous pairs of Rbs (arm combinations: 2.4, 3.6, $5.15,7.8,9.14,10.12,11.13,16.17$; numbers refer to the corresponding telocentric chromosome of the standard mouse karyotype). Last year, during a dioxin risk assessment 
survey in the village of Seveso ${ }^{7}$, we captured 23 mice from 3 sites which all had the same karyotype $(2 n=24)$ and 8 homozygous pairs of Rbs (S. G., M. Z., C. A. R. \& E. C., manuscript in preparation). The arm combinations $(2.12,3.4,5.15,6.7,8.11,9.14$, $10.13,16.17)$ are different from those expected of the Milan I population, even though Seveso lies within the Milan I distributional area.

The two populations share only three ubiquitous Rbs: 5.15, 9.14 and 16.17 . $\mathrm{Rb}(2.12)$ and $\mathrm{Rb}(8.11)$ have arm combinations that have not previously been described. A comparison with the karyotypes of the surrounding populations ${ }^{8}$ (Milan II, Luino, Lower Valtellina and Cremona) shows that the origin of the Seveso Rbs may be traced parsimoniously from the parapatric $2 n=24$ Milan II population (Rbs: 2.8, 3.4, 5.15, 6.7, 9.14, 10.12, 11.13, 16.17) from whole-arm reciprocal translocations (WART) among $\mathrm{Rb}(2.8), \mathrm{Rb}(10.12)$ and $\mathrm{Rb}(11.13)$.

The origin of some of the current $\mathrm{Rb}$ populations can be traced back by WARTs among Rbs of a hypothetical ancestral $\mathrm{Rb}$ population $^{1,5,9}$ and an actual case of a heterozygous $\mathrm{Rb}$ mouse with karyotype derived through WARTs has been described $^{9}$. We suggest that Seveso mice originated over no more than 20 years from the time of massive material movements (during scarification, 1977-1984, and reconstruction, 1985-1994) which favoured contraction and expansion of the Milan I and Milan II territories. Hauffe and Searle ${ }^{3}$ described a disappearing speciation event in a similarly small village, the surrounding area of which was affected by enormous earth movements (avalanches and floods).

The possible repeated occurrence of appearing and disappearing speciation events could greatly shorten the time needed for new chromosomal races to establish themselves. They could form or disappear within a few decades, a period of time never before suspected. Such events could also better explain the patchy present-day distribution of the house mouse $\mathrm{Rb}$ races. The Seveso chromosomal race changes will be worth monitoring.

\section{Silvia Garagna, Maurizio Zuccotti ${ }^{\star}$}

\section{Carlo Alberto Redi}

Dipartimento di Biologia Animale e Centro di Studio per l'Istochimica del C.N.R.,

Università di Pavia, Piazza Botta,

9-27100 Pavia, Italy

* and Fondazione Lombardia per L'Ambiente,

Foro Bonaparte, 12, 20121 Milano, Italy

e-mail: garagna@ipv36.unipv.it

Ernesto Capanna

Dipartimento di Biologia Animale

e dell'Uomo,

Università di Roma

"La Sapienza", Via A. Borelli, 50-00161

Roma, Italy
1. King, M. Species Evolution. The Role of Chromosome Change (Cambridge Univ. Press, 1993).

2. Gropp, A., Winking, H. \& Redi C. A. in Genetic Control of Gamete Production and Function (eds Crosignani, P. G. \& Rubin, B. L.) 115-134 (Grune and Stratton, New York, 1982). Hauffe, H. C. \& Searle, J. B. Nature 357, 26 (1992).

4. Capanna, E. \& Corti, M. Mammalia 46, 107-109 (1982).

5. Nachman, M. W. \& Searle, J. B. Trends Ecol. Evol. 10, 397-402 (1995)

6. Britton-Davidian, J. et al. Genet. Res. 53, 29-44 (1989).

7. Hay, A. Nature 262, 636-638 (1976).

8. Redi, C. A. \& Capanna, E. in The Cytogenetics of Mammalian Autosomal Rearrangements (ed. Daniel, A.) 315-359 (Alan R. Liss, New York, 1988).

9. Capanna, E. \& Redi, C. A. Chromosome Res. 3, 135-137 (1995).

\section{Sex ratio unaffected by}

\section{parental age gap}

Sex ratios based on a small sample of births tend to be very unstable. It is therefore not surprising that Manning et al. found a relationship between spousal age differences and the sex ratios at birth for a very small sample from a restricted population ${ }^{1}$. Their findings do not stand up to scrutiny when tested with larger, representative samples of births.

We examined the sex ratio at birth (males per 100 females) for a pooled sample of 467,693 births to women of reproductive age (ages 15-49) in 12 less-developed countries with a wide range of overall fertility levels. The data come from the Demographic and Health Surveys (DHS), which collected information from nationally representative samples of women in each country between 1992 and 1997. The total fertility rate in these countries ranges from more than six lifetime births per woman in sub-Saharan African countries such as Mali and Zambia to a near-replacement level of fertility of 2.5 births per woman in countries such as Brazil and Kazakstan. The largest survey, the National Family Health Survey of India, was not formally part of the DHS programme, but used similar questionnaires and survey procedures. Information on births was collected in face-to-face interviews with mothers in the birth-history section of the questionnaire. Because the surveys did not collect information on the ages of previous partners, our analysis is restricted to women who are currently married or living with a man and have been married only once.

Table 1 shows the findings for three different groups: men who are at least five years older than their wives; men who are older than their wives by less than five years; and men who are younger than their wives.
The most significant observation is that sex ratios at birth vary hardly at all by either the birth order or the relative ages of the parents. The overall sex ratio of 105.9 for all births is in the middle of the normal range of 105-107 that has been observed in most parts of the world ${ }^{2}$. Men married to older women are slightly more likely than other men to have male children, but the difference is not large.

Because Manning et al. found large differences only for first births, we separated total births into first births $(N=127,176)$ and all subsequent births $(N=340,517)$. For first births, the differences are even smaller than those observed for total births. Moreover, the slight difference that is evident is in the opposite direction to the pattern found by Manning et al. (husbands much older than their wives are slightly less likely to have male children than are other husbands).

We also conducted a similar analysis controlling for age of husband. Again, the analysis failed to confirm the results found in the small sample in England. Finally, we examined the results separately for each of the 12 countries included in the pooled sample. The individual country findings confirm the lack of any consistent pattern of sex-ratio differences in relation to the relative ages of the spouses. In seven countries, the sex ratio at birth was somewhat lower for husbands married to much younger women than for other husbands (contrary to the findings of Manning et al.). In the other five countries, the reverse was true.

In conclusion, no matter whom you marry, your chances of having a male child for any given live birth are about 51.4 per cent, which corresponds to a sex ratio at birth of 105.9 males per 100 females.

Fred Arnold, Shea Rutstein

Demographic and Health Surveys,

Macro International, 11785 Beltsville Drive,

Calverton, Maryland 20705, USA

e-mail:arnold@macroint.com

J. T. Manning et al. ${ }^{1}$ categorized the sexes of children by birth order and by difference between parents' ages. There was an excess of first-born sons when the father was 5 years older than the mother, and an excess of first-born daughters when the father was one or more years younger than the mother.

A study ${ }^{3}$ presented data on 1.4 million single, white, live births in New York State from 1959 to 1967 , categorized by maternal age, paternal age and birth order. Maternal and paternal age were categorized into five-

\begin{tabular}{|c|c|c|c|c|}
\hline \multirow[b]{2}{*}{ Birth order } & \multicolumn{3}{|c|}{ Difference in age of husband and wife } & \multirow[b]{2}{*}{ Total } \\
\hline & $\begin{array}{l}\text { Wife older } \\
\text { than husband }\end{array}$ & $\begin{array}{c}\text { Husband less than } \\
5 \text { years older than wife }\end{array}$ & $\begin{array}{c}\text { Husband at least } \\
5 \text { years older than wife }\end{array}$ & \\
\hline First birth & 107.5 & 107.5 & 106.9 & 107.2 \\
\hline $\begin{array}{l}\text { Second or } \\
\text { subsequent birth }\end{array}$ & 106.5 & 105.6 & 105.3 & 105.4 \\
\hline Total & 106.7 & 106.1 & 105.7 & 105.9 \\
\hline
\end{tabular}

